\title{
Surgical Cytoreduction and HITOC for Thymic Malignancies with Pleural Dissemination
}

\author{
Till Markowiak ${ }^{1}$ Reiner Neu ${ }^{1}$ Mohammed Khalid Afeen Ansari ${ }^{1} \quad$ Christian Großer $^{2}$ \\ Monika Klinkhammer-Schalke ${ }^{3}$ Hans-Stefan Hofmann ${ }^{1,2}$ Michael Ried ${ }^{1}$
}

${ }^{1}$ Department of Thoracic Surgery, University Medical Center Regensburg, Regensburg, Germany

2 Department of Thoracic Surgery, Hospital Barmherzige Brüder Regensburg, Regensburg, Germany

3 Tumor Center, University Institute of Quality Assurance and Health Services Research, Regensburg, Germany

Thorac Cardiovasc Surg 2021;69:157-164.
Address for correspondence Michael Ried, MD, Department of Thoracic Surgery, University Medical Center Regensburg, Franz-JosefStrauß Allee 11, Regensburg 93053, Germany

(e-mail: micha.ried@t-online.de).

\begin{abstract}
Background Objective of this study was to assess postoperative morbidity and mortality as well as recurrence-free and overall survival in patients with thymic malignancies and pleural dissemination undergoing surgical cytoreduction and hyperthermic intrathoracic chemotherapy (HITOC).

Methods Retrospective study between September 2008 and December 2017 with follow-up analysis in May 2018.

Results A total of 29 patients (male: $n=17$ ) with thymic malignancies and pleural spread (primary stage IVa: $n=11$; pleural recurrence: $n=18$ ) were included. Surgical cytoreduction was performed via pleurectomy/decortication (P/D; $n=11)$, extended P/D $(n=15)$, and extrapleural pneumonectomy (EPP; $n=3)$. These procedures resulted in $25(86 \%)$ patients with macroscopically complete (R0/R1) resection. Intraoperative HITOC was performed for 60 minutes at $42^{\circ} \mathrm{C}$ either with cisplatin $\left(100 \mathrm{mg} / \mathrm{m}^{2}\right.$ body surface area $[\mathrm{BSA}] n=8 ; 150 \mathrm{mg} / \mathrm{m}^{2} \mathrm{BSA} n=6 ; 175 \mathrm{mg} / \mathrm{m}^{2} \mathrm{BSA} n=1$ ) or with a combination of cisplatin $\left(175 \mathrm{mg} / \mathrm{m}^{2} \mathrm{BSA}\right) /$ doxorubicin $(65 \mathrm{mg} ; n=14)$. Postoperative complications occurred in nine patients (31\%). Cytoprotective therapy resulted in lower postoperative creatinine levels $(p=0.036)$, and there was no need for temporary dialysis in these patients. The 90-

Keywords

- tumor

- thymus

- surgery

- complications

- pleural disease day mortality rate was $3.4 \%$, as one patient developed multiple organ failure. While recurrence-free 5 -year survival was $54 \%$, an overall 5 -year survival rate of $80.1 \%$ was observed. Survival depended on histological subtype $(p=0.01)$.

Conclusion Surgical cytoreduction with HITOC is feasible in selected patients and offers encouraging survival rates. The application of cytoprotective agents appears to be effective for the prevention of postoperative renal insufficiency.
\end{abstract}

\section{Introduction}

The prognosis of patients with malignant thymic epithelial tumors (thymoma, thymic carcinoma) correlates closely with postoperative resection-status, histological subtype, and Masaoka-Koga stage. ${ }^{1}$ In early stages, radical surgical resection of the thymic tumor is still the recommended treatment. ${ }^{2}$ While these patients with early tumor stages (MasaokaKoga stage I and II) have excellent prognosis, patients with more invasive thymic malignancies show high rates of local recurrence and, thus, poor long-term survival. ${ }^{3,4}$ MasaokaKoga and TNM stage IVa is defined as pleural or pericardial received

May 13, 2019

accepted after revision

September 22, 2019

published online

November 15, 2019 (c) 2019. Thieme. All rights reserved.

Georg Thieme Verlag KG,

Rüdigerstraße 14,

70469 Stuttgart, Germany
DOI https://doi.org/

10.1055/s-0039-1700883. ISSN 0171-6425. 
tumor spread, which includes both primary tumors and recurrent pleural tumors. Considering only patients with thymic malignancies (thymoma) in stage IVa, 5-year survival rates of 53 to $87 \%$ were reported after surgical resection. ${ }^{5,6}$ A tumor of this extent is difficult to treat with surgical procedures because residual tumor cells often remain in the pleural cavity, leading to pleural recurrences. ${ }^{7-9}$ Therefore, advanced stages require a multimodal treatment approach involving systemic chemotherapy, radiotherapy, or radio/ chemotherapy. They can be combined with surgery in neoadjuvant and adjuvant settings or used stand-alone with a palliative intention. ${ }^{6,10}$ Systemic therapies have been reported to show only temporary impact on tumor progression. ${ }^{11}$ Curative therapy for this advanced stage is not yet known. ${ }^{12}$

An innovative technique that is expected to improve local tumor control in patients with pleural tumor involvement is surgical cytoreduction followed by hyperthermic intrathoracic chemotherapy (HITOC). The HITOC approach is based on the dose-response principle, whereby locally high doses of chemotherapeutic agents can be achieved in the pleural cavity with minimal absorption. ${ }^{11}$ Very few studies exist on this innovative procedure in patients with thymic malignanices. ${ }^{11,13-15}$ Nevertheless, this procedure shows promising results for patient safety in the existing literature, while the effect on overall survival and recurrence-free survival requires further investigation. ${ }^{7}$

\section{Patients and Methods}

\section{Study Design}

This is a retrospective, single-center study of patients with thymic malignancies according to Masaoka-Koga/TNM stage IVa and primary pleural dissemination or pleural recurrence. All patients who received a radical tumor resection (surgical cytoreduction) with subsequent HITOC from September 2008 to December 2017 were included $(n=29)$. The main tumor manifestation was located at the pleural surface, sometimes even involving the pericardium, the diaphragm, or the lung. Lymph node sampling was performed if suspected lymph nodes appeared intraoperatively.

The study was approved by our institutional ethics committee, and informed consent was obtained from all patients. Demographic data, surgical parameters, data regarding HITOC, and postoperative data were documented. The follow-up examination was performed in May 2018 by the regional Tumor Centre Regensburg. Tumor recurrence was defined by computed tomography scan or positron emission tomography scan. Recurrence-free interval and overall-survival were examined.

The primary end point of the study was to determine postoperative morbidity with special respect to renal insufficiency and mortality after surgical cytoreduction including HITOC. Secondary end points included the recurrence-free and overall-survival.

\section{Surgical Cytoreduction}

Depending on the location of the tumor, different surgical procedures were used for cytoreduction. Almost all patients received two anterolateral thoracotomies (5th and 8th inter- costal space) for an optimal view and inspection of the whole thoracic cavity. The procedures included pleurectomy/ decortication $(\mathrm{P} / \mathrm{D})$, extended $\mathrm{P} / \mathrm{D}(\mathrm{eP} / \mathrm{D}$ including resection of the pericardium and/or diaphragm and/or lung resection), and extrapleural pneumonectomy (EPP). Lung-sparing procedures (P/D and eP/D) were preferred for cytoreduction if possible. Therefore, an extrapleural dissection between lung and tumor was performed after anterolateral thoracotomy. A pleurectomy was performed from the apex to the diaphragm until the hilar structures were free. The visceral pleura was then separated from the lung. If necessary, wedge resections of infiltrated parts of the lung or resections of the pericardium, diaphragm, or chest wall were performed (eP/D). Resected areas of the pericardium or diaphragm were reconstructed and covered with bovine patches. Only in selected patients with extensive tumor invasion an EPP was performed. These tumors were primarily located in the anterior mediastinum and infiltrated the pleural cavity and lung parenchyma. In these patients, a macroscopic complete tumor resection was only reachable by EPP.

\section{HITOC Procedure}

If possible, HITOC was performed right after the surgical cytoreduction in the same session. For the safety of the staff, the procedure was always performed with a closed chest. At least one apical inflow drainage and two or three basal outflow drainages were placed before the thoracotomies were closed. The drains were connected to the perfusion system (ThermoChemo HT1000) and 3 to $4 \mathrm{~L}$ sodium chloride was introduced into the circulation as priming volume while the system was heated to a temperature of $42^{\circ} \mathrm{C}$ measured at the outflow drains. As soon as circulation was stable, the chemotherapeutic agents were added. The dosage of chemotherapeutic agents was increased over the course of the study because the patients rarely presented cisplatin-related complications and also higher dosages showed better survival in mesothelioma patients in the literature. In the beginning of the study, cisplatin was used at a dose of $100 \mathrm{mg} / \mathrm{m}^{2}$ body surface area (BSA), which was later increased to $175 \mathrm{mg} / \mathrm{m}^{2}$ BSA and combined with $65 \mathrm{mg}$ doxorubicin. The perfusion was performed over a period of 60 minutes with a flow rate of $\sim 1.5 \mathrm{~L} /$ min. Afterward, the perfusion solution was drained and the drains left for the early postoperative period. During the operation and for approximately the first five days postoperatively we aimed a fluid balancing and a forced diuresis $>100 \mathrm{~mL} / \mathrm{h}$. Starting in June 2013, we added amifostine and sodium thiosulfate to reduce renal toxicity from cisplatin as reported by the working group of Dr. Sugarbaker et al. ${ }^{16,17}$ Amifostine was given intravenously in a dosage of $910 \mathrm{mg} / \mathrm{m}^{2}$ BSA 30 minutes prior to the initiation of the HITOC. Sodium thiosulfate was administered directly after $\operatorname{HITOC}\left(4 \mathrm{~g} / \mathrm{m}^{2} \mathrm{BSA}\right)$ and continuously over a period of 6 hours $\left(12 \mathrm{~g} / \mathrm{m}^{2} \mathrm{BSA}\right)$ at the intensive care unit.

\section{Statistical Analysis}

The data were collected in tabular form using Excel, Version 15.0 (Microsoft Corporation, Redmond, Washington, United States). Afterward, statistical analysis was performed using 
IBM SPSS Statistics, Version 24 (IBM Corporation, Armonk, New York, United States). The demographic data were summarized as numbers and percentages. Student's $t$-test and Mann-Whitney $\mathrm{U}$ tests were used for group comparisons if appropriate. The Kaplan-Meier method was used for the analysis of recurrence-free survival and overall-survival. Recurrence-free and overall-survival were defined as the interval between treatment and the occurrence of tumor recurrence, death or last follow-up. The log-rank test was used to examine the influence of tumor type, histological subtype, postoperative resection status, and the combination of chemotherapeutic agents on survival. A $p$-value $<0.05$ was considered statistically significant.

\section{Results}

\section{Demographic Data}

The mean age of the study population was 49 years, and $58.7 \%$ of patients were male ( - Table 1 ). In $\sim 52 \%$ of patients, the pleural tumor dissemination was located on the right side. Eleven (37.9\%) patients had thymic malignancies with primary pleural tumor spread (primary stage IVa) when they were scheduled for surgery for the first time, while 18 (62.1\%) patients showed pleural tumor recurrence (secondary stage IVa) after previous surgery of thymic tumors. The median interval between first diagnosis of the thymic tumor and pleural reoperation (surgical cytoreduction) including HITOC in these patients was 36 months (interquartile range 37.5

Table 1 Demographic data

\begin{tabular}{|c|c|}
\hline & $\begin{array}{l}\text { Study sample } \\
(n=29 ; 100 \%)\end{array}$ \\
\hline Male gender & $17(58.7)$ \\
\hline Mean age \pm SD (years) & $49 \pm 12.2$ \\
\hline Mean $\mathrm{BMI} \pm \mathrm{SD}\left(\mathrm{kg} / \mathrm{m}^{2}\right)$ & $26.2 \pm 4.9$ \\
\hline Mean $\mathrm{BSA} \pm \mathrm{SD}\left(\mathrm{m}^{2}\right)$ & $1.93 \pm 0.23$ \\
\hline Tumor localization on the right side & $15(51.7)$ \\
\hline \multicolumn{2}{|l|}{ Tumor } \\
\hline - Primary tumor & 11 (37.9) \\
\hline - Recurrence & $18(62.1)$ \\
\hline Induction therapy & $15(51.7)$ \\
\hline \multicolumn{2}{|l|}{ Who } \\
\hline - B1 & $4(13.8)$ \\
\hline - B2 & $10(34.5)$ \\
\hline - $\mathrm{B} 2 / 3$ & $5(17.2)$ \\
\hline - B3 & $7(24.2)$ \\
\hline - $\mathrm{C}$ & $3(10.3)$ \\
\hline $\begin{array}{l}\text { Patients with recurrent thymoma: } \\
\text { Median interval first diagnosis - } \\
\text { reoperation with HITOC; } \\
\text { IQR (months) }\end{array}$ & $36 ; 37.5$ \\
\hline
\end{tabular}

Abbreviations: BMI, body mass index; BSA, body surface area; HITOC, hyperthermic intrathoracic chemotherapy; IQR, interquartile range; SD, standard deviation; WHO, World Health Organization. months). The most frequent histological subtype in the study population was World Health Organization (WHO) grade B2 ( $n=10 ; 34.5 \%)$, followed by grade B3 $(n=7 ; 24.2 \%)$. In three cases (10.3\%), participants suffered from a thymic carcinoma (WHO grade C). In 15 cases (51.7\%), induction therapy was performed prior to resection to downsize the tumor and increase the chance for complete tumor resection.

\section{Operative Data}

- Table 2 shows the operative parameters. Most patients received eP/D $(n=15 ; 51.8 \%)$. For almost all patients ( $n=27$; $93.1 \%)$, HITOC was performed after the resection in the same session. In two cases (6.9\%) with extensive surgical tumor resection and hemodynamic instability, all thoracic drains were placed as described above and HITOC was performed 1 and 19 days later. The initially used dose of $100 \mathrm{mg} / \mathrm{m}^{2}$ BSA cisplatin was applied to eight patients (27.6\%). In seven patients (24.2\%), the cisplatin dose ranged between 150 and $175 \mathrm{mg} / \mathrm{m}^{2}$ BSA. In the later study period and with increased experiences, most patients received a combination of cisplatin and doxorubicin, with cisplatin at the maximum dosage of $175 \mathrm{mg} / \mathrm{m}^{2} \mathrm{BSA}(n=14 ; 48.2 \%)$. Average operation time including HITOC was 275 minutes (min: 118 minutes, max: 440 minutes).

\section{Postoperative Data}

In $25(86.2 \%)$ patients, a macroscopically complete tumor resection (R0/R1) was achieved. Four patients had macroscopically residual tumors (R2: 13.8\%). In two patients, a transdiaphragmal, intra-/retroperitoneal spread of the tumor was observed. These resections with macroscopically low tumor residues were intraoperatively classified as $\mathrm{R} 2$. Other two

Table 2 Operative data including HITOC

\begin{tabular}{|c|c|}
\hline & $\begin{array}{l}\text { Study sample } \\
(n=29 ; 100 \%)\end{array}$ \\
\hline \multicolumn{2}{|l|}{ Surgical cytoreduction } \\
\hline$\cdot \mathrm{P} / \mathrm{D}$ & $11(37.9)$ \\
\hline - eP/D & $15(51.8)$ \\
\hline - EPP & $3(10.3)$ \\
\hline \multicolumn{2}{|l|}{ HITOC } \\
\hline - Same session & $27(93.1)$ \\
\hline - Second session & $2(6.9)$ \\
\hline \multicolumn{2}{|l|}{ Chemotherapeutics } \\
\hline - Cisplatin $100 \mathrm{mg} / \mathrm{m}^{2} \mathrm{BSA}$ & $8(27.6)$ \\
\hline - Cisplatin $150-175 \mathrm{mg} / \mathrm{m}^{2} \mathrm{BSA}$ & $7(24.2)$ \\
\hline $\begin{array}{l}\text { - Cisplatin } 175 \mathrm{mg} / \mathrm{m}^{2} \mathrm{BSA}+ \\
\text { doxorubicin } 65 \mathrm{mg}\end{array}$ & $14(48.2)$ \\
\hline Cytoprotection & $16(55.2)$ \\
\hline $\begin{array}{l}\text { Mean duration of } \\
\text { operation } \pm S D \text { (minutes) }\end{array}$ & $275 \pm 79$ \\
\hline
\end{tabular}

Abbreviations: BSA, body surface area; eP/D, extended pleurectomy/ decortication; EPP, extrapleural pneumonectomy; HITOC, hyperthermic intrathoracic chemotherapy; $P / D$, pleurectomy/decortication; SD, standard deviation. 
Table 3 Postoperative data

\begin{tabular}{|c|c|}
\hline & $\begin{array}{l}\text { Study sample } \\
(n=29 ; 100 \%)\end{array}$ \\
\hline \multicolumn{2}{|l|}{ Resection } \\
\hline - R0/1 & $25(86.2)$ \\
\hline - R2 & $4(13.8)$ \\
\hline Median ICU stay; IQR (d) & $1 ; 2$ \\
\hline Median hospital-stay; IQR (d) & $18 ; 18$ \\
\hline Intraoperative complications & $1(3.4)$ \\
\hline Postoperative complications & $9(31)$ \\
\hline - Surgical revision required & $6(20.7)$ \\
\hline - Postoperative dialysis & $2(6.9)$ \\
\hline $\begin{array}{l}\text { - Postoperative } \\
\text { pulmonary embolism }\end{array}$ & $1(3.4)$ \\
\hline In-hospital mortality & $1(3.4)$ \\
\hline 90-d mortality & $1(3.4)$ \\
\hline Adjuvant chemotherapy & $13(44.8)$ \\
\hline Adjuvant radiotherapy & $8(27.6)$ \\
\hline
\end{tabular}

Abbreviations: ICU, intensive care unit; IQR, interquartile range; SD, standard deviation.

patients showed infiltration of the superior or inferior vena cava so that tumor debulking was performed. Since a complete resection could not be determined with certainty, they were also classified as R2. Intraoperative complications occurred only in one $(3.4 \%)$ patient (temporary right heart decompensation before HITOC). Surgical revision was necessary in a total of $\operatorname{six}(20.7 \%)$ patients. Half of these patients $(n=3)$ suffered from a prolonged parenchymal fistula after extensive decortication, which made a rethoracotomy with suture of the lung parenchyma necessary. The other three cases included patch rupture of the diaphragm (re-attachment), chylothorax (closure of lymphatic fistula), and hemothorax (evacuation of hematoma). One patient developed pulmonary embolism, which could be treated with anticoagulation. Another patient developed sepsis with subsequent multiple organ failure and died in the hospital. The median stay in the intensive care unit was 1 day, and the total stay in the hospital was 18 days. In 13 patients (44.8\%), adjuvant chemotherapy was performed, and eight (27.6\%) patients received adjuvant radiotherapy, depending on the resection status and the histological subtype (-Table 3).

\section{Postoperative Renal Function}

Only a moderate increase in serum creatinine levels was observed in the first postoperative days. Looking at all patients, the collected data showed a maximum mean value of creatinine of $1.13 \mathrm{mg} / \mathrm{dL} 2$ days after surgery. As illustrated in - Fig. $\mathbf{1}$, patients who received amifostine and sodium thiosulfate for cytoprotection showed an overall milder increase in serum creatinine. In patients without cytoprotection, the maximum was reached after 1 week and was higher overall $1.24 \mathrm{mg} / \mathrm{dL}$. At this time, patients with cytoprotection showed a considerably lower creatinine level of $0.7 \mathrm{mg} / \mathrm{dL}$. The differences in median serum creatinine levels turned out to be statistically significant $(p=0.036)$, although this finding was not clinically relevant. Despite the increasing cisplatin concentration during the study and the subsequent combination with doxorubicin, there was no increased rate of postoperative renal insufficiency. Postoperative temporary dialysis was necessary in two patients (6.9\%) in the early study period without cytoprotection (-Table 3 ).

\section{Survival Analysis}

Overall survival and recurrence-free survival are shown in - Fig. 2. One patient with thymic carcinoma died after EPP during hospital stay (30-day mortality 3.4\%) and was, therefore,

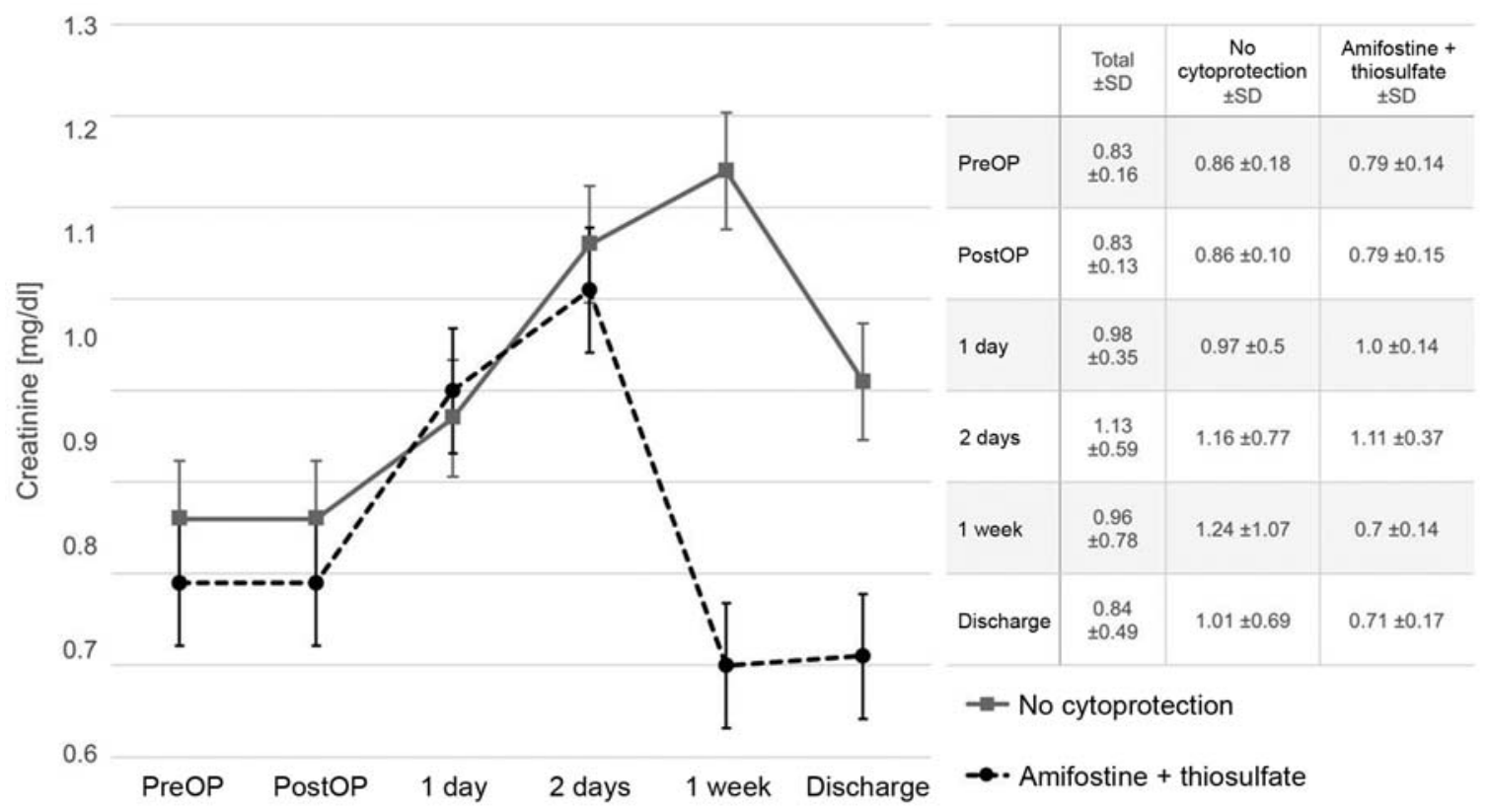

Fig. 1 Serum creatinine concentration after surgical cytoreduction and hyperthermic intrathoracic chemotherapy. SD, standard deviation. 


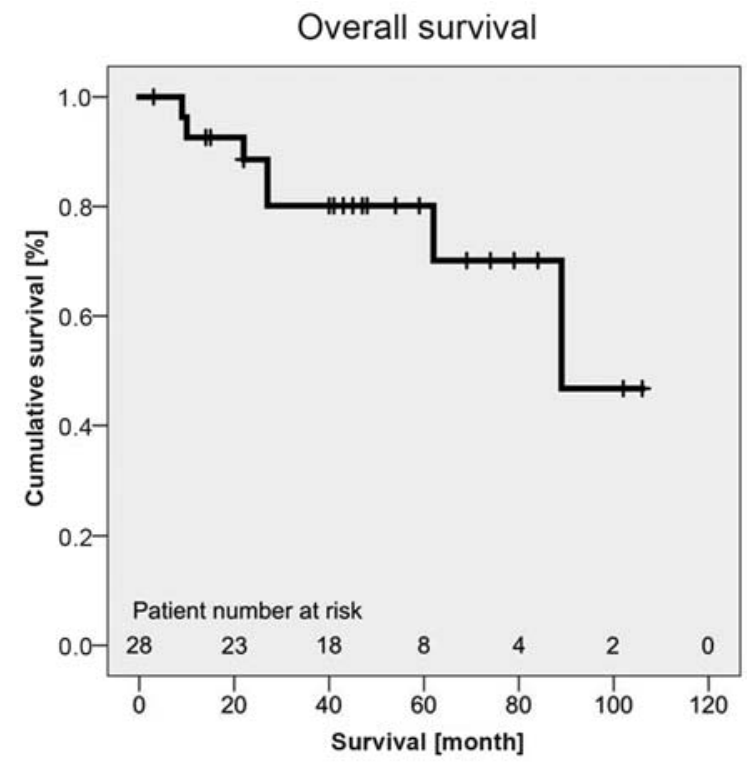

\begin{tabular}{|l|c|}
\hline & 5-year survival rate [\%] \\
\hline All thymoma patients $(n=28)$ & 80.1 \\
\hline
\end{tabular}

Fig. 2 Overall survival and recurrence-free survival.

excluded from the long-term survival analysis. A 5-year survival rate of $80.1 \%$ was observed in all patients $(n=28)$. The mean follow-up was 35.6 months (min: 0 months, max: 106 months). At the end of the follow-up, $62.5 \%$ of the patients were alive, and the recurrence-free survival after 5 years was $53.8 \%$ for patients with R0/R1 resection $(n=24)$. The median recurrence-free interval was 69 months (95\% confidence interval: 40.4-97.6; min: 0 months, max: 69 months). Concerning

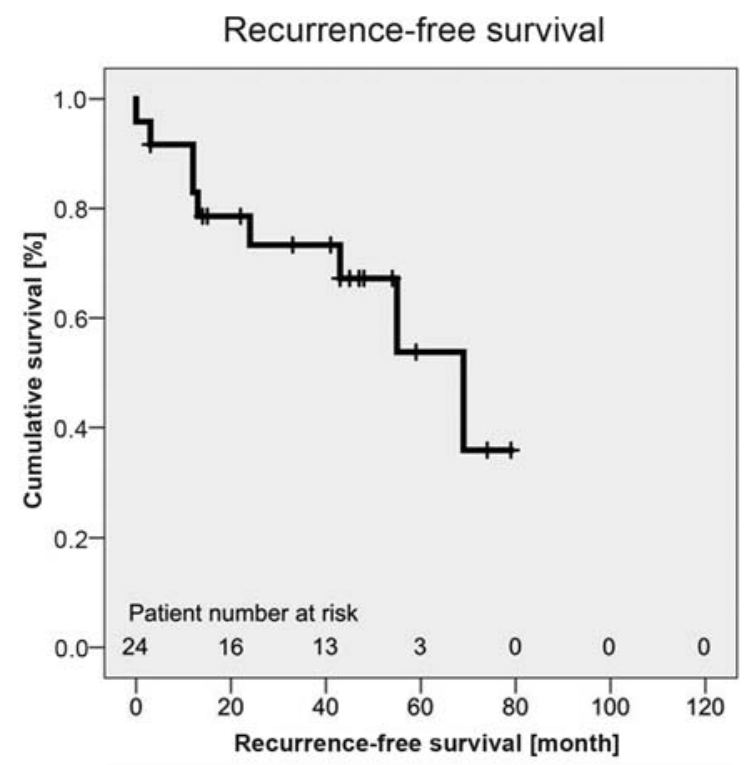

\begin{tabular}{|c|c|}
\hline & $\begin{array}{c}\text { 5-year recurrence-free } \\
\text { survival rate [\%] }\end{array}$ \\
\hline $\begin{array}{c}\text { Patients after R0/R1 } \\
\text { resection }(n=24)\end{array}$ & 53.8 \\
\hline
\end{tabular}

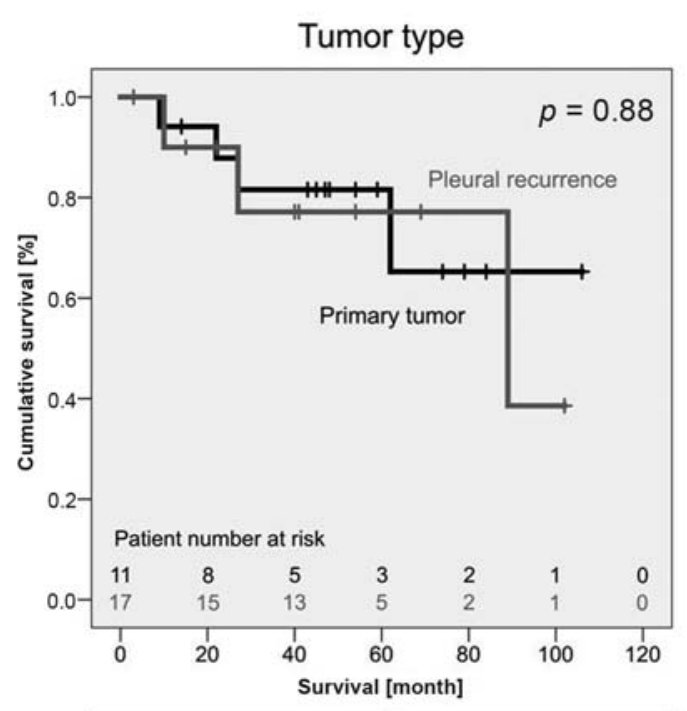

\begin{tabular}{|l|c|}
\hline & 5-year survival rate [\%] \\
\hline Primary tumor $(n=11)$ & 81.6 \\
Pleural recurrence $(n=11)$ & $\mathbf{7 7 . 1}$ \\
\hline
\end{tabular}

recurrence-free survival, no significant prolongation was observed by combining cisplatin with doxorubicin $(p=0.59)$. The log-rank test showed no significant difference in survival between patients with primary pleural tumors and patients with pleural recurrence $(p=0.88)$. Concerning histological subtypes, the lowest survival was found in patients with thymic carcinoma $(p=0.01 ;$ - Fig. 3 ). No difference in survival could be observed by resection status $(p=0.394)$ or by choice of

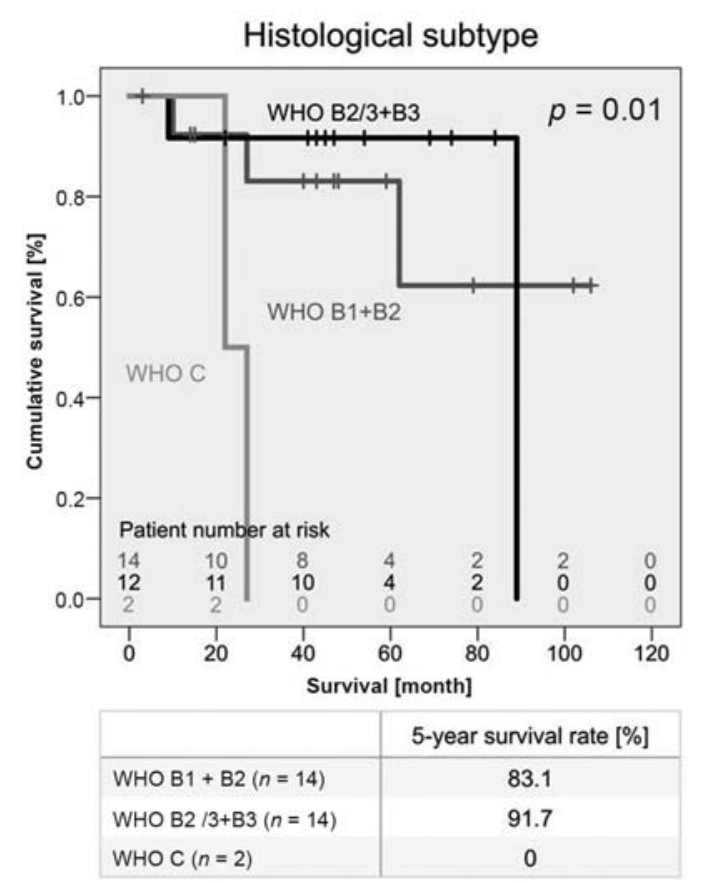

Fig. 3 Survival depending on type of tumor and histological subtype. WHO, World Health Organization. 

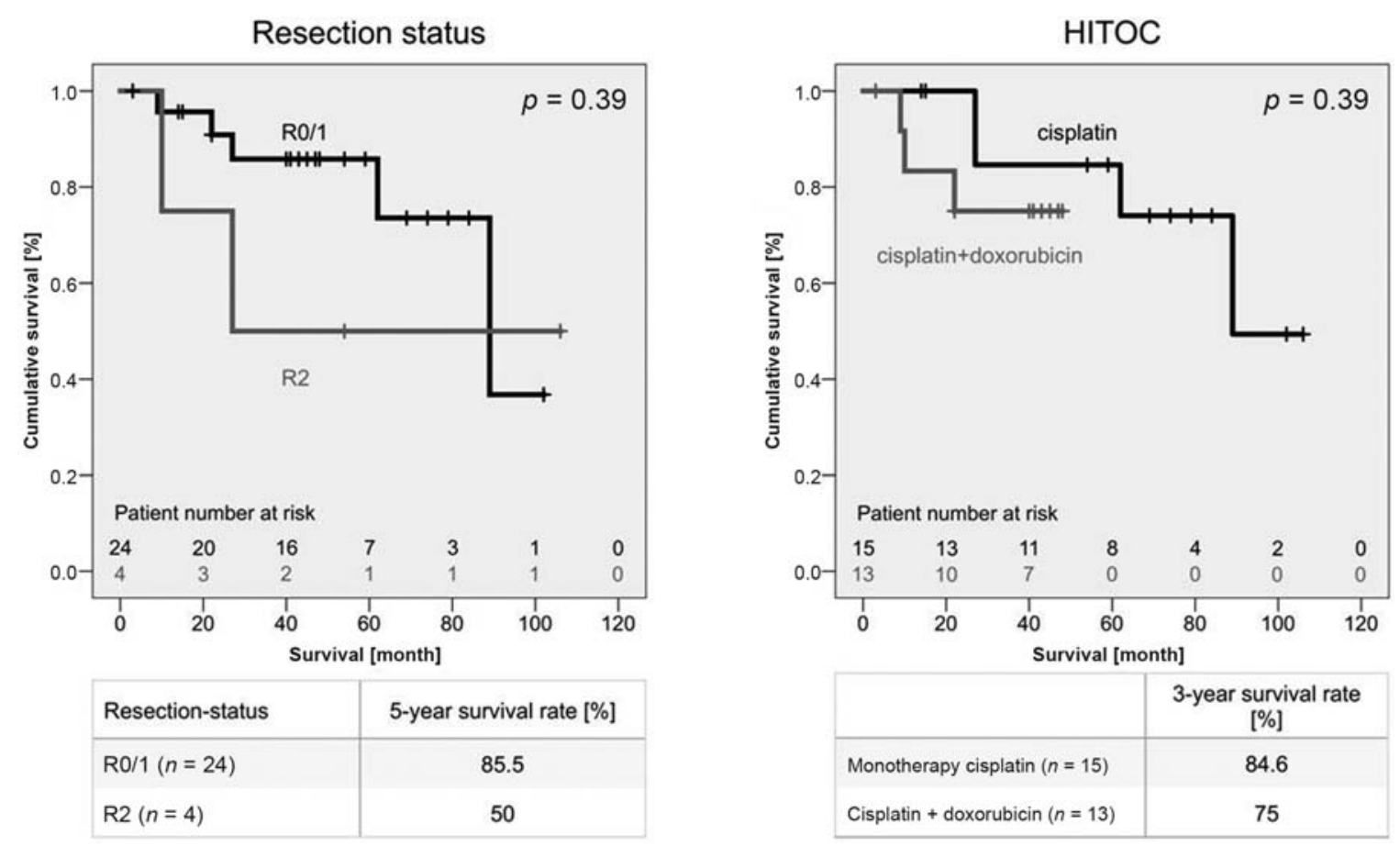

Fig. 4 Survival depending on resection status and chemotherapy for hyperthermic intrathoracic chemotherapy (HITOC).

chemotherapeutic agents for HITOC $(p=0.39)$. The corresponding graphs and associated rates are presented in -Fig. 4. Similarly, no difference was observed by the concentration of cisplatin $(p=0.99)$ or the surgical procedure used $(p=0.27)$.

\section{Discussion}

The treatment of patients with thymic malignancies and pleural dissemination (stage IVa) has been the subject of controversial discussions. ${ }^{3,4}$ Combinations of surgical cytoreduction and radiochemotherapy currently represent the gold standard in treatment, but the beneficial effects of systemic therapies are limited. However, the advantages of additional local HITOC are still not clear. ${ }^{11}$ Most clinical experience with HITOC has been gained in the treatment of malignant pleural mesothelioma with a prolongation of overall-survival (35.3 vs. 22.8 months). ${ }^{7,18}$

In our study, HITOC was performed either with cisplatin alone or in combination with doxorubicin. Cisplatin is wellknown as first-line therapy for thymomas in systemic approaches. ${ }^{6}$ In the literature, cisplatin is always a component for HITOC. A maximum tolerable dose of cisplatin of $225 \mathrm{mg} / \mathrm{m}^{2}$ BSA was determined in a previous mesothelioma study and we also increased the dosage of cisplatin during the study as higher doses demonstrated a better survival in patients with malignant pleural mesothelioma. ${ }^{16,19}$ We expected that also in thymoma patients an increased dosage would lead to better long-term results. The use of a second agent, however, differs and is still debated. While some studies use cisplatin alone, others combine it with a second substance, often an anthracycline. ${ }^{13-15,20}$ In our study, the addition of doxorubicin did not yet significantly prolong overall and recurrence-free survival. For this reason, excluding doxorubicin could be considered.

It has already been proven that only a fraction of the cisplatin concentration of the intrathoracic perfusion solution passes into the serum. ${ }^{21,22}$ Nevertheless, systemic complications caused by chemotherapeutic agents (cisplatin concentration) have to be considered. ${ }^{19}$ Cisplatin has dosedependent renal toxicity, and the most important chemotherapy-related complication to be mentioned here is the postoperative increase in creatinine. Moderate-to-severe nephrotoxicity was noted in 25 to $33 \%$ of patients receiving a single intravenous dose of cisplatin of 50 to $75 \mathrm{mg} / \mathrm{m}^{2} .^{23} \mathrm{In}$ several studies, HITOC caused renal dysfunction in 8.7 to $57 \%$ of patients. ${ }^{19,24}$

To attenuate cisplatin-induced nephrotoxicity, fluid balancing including hydration (with diuresis as needed) is generally introduced in the cisplatin-based chemotherapy regimen as a nephroprotective strategy. ${ }^{25}$

In our opinion, additional cytoprotection is one of the most important tasks during HITOC. Amifostine pretreatment should reduce tubulotoxicity and sodium thiosulfate is a neutralizing agent for cisplatin that also protects against renal damage. ${ }^{26}$ The application of amifostine and sodium thiosulfate as cytoprotective agents significantly reduced creatinine levels in the postoperative period during the study. The two patients in our study with postoperative transient dialysis were treated at the beginning of our HITOC program without cytoprotection. After the introduction of cytoprotection, no dialysis was necessary despite the increase in cisplatin concentration and the additional combination with doxorubicin. Few other studies have already reported the positive effect of cytoprotection on renal function. ${ }^{16,17}$ 
Table 4 Study overview of stage IVa thymic tumors and application of HITOC

\begin{tabular}{|l|l|l|l|l|l|}
\hline Author, $y$ & Patients & Chemotherapeutics (dosage) & Mortality & $\begin{array}{l}\text { Recurrence } \\
\text { free survival }\end{array}$ & Overall survival \\
\hline Refaely et al, $2001^{14}$ & $n=15$ & Cisplatin $\left(100-200 \mathrm{mg} / \mathrm{m}^{2} \mathrm{BSA}\right)$ & $0 \%$ & - & $70 \%(5 \mathrm{y})$ \\
\hline de Bree et al, $2002^{11}$ & $n=14$ & $\begin{array}{l}\text { Cisplatin }\left(80 \mathrm{mg} / \mathrm{m}^{2} \mathrm{BSA}\right)+ \\
\text { doxorubicin }\left(15-30 \mathrm{mg} / \mathrm{m}^{2} \mathrm{BSA}\right)\end{array}$ & $0 \%$ & $100 \%(18 \mathrm{mo})$ & $100 \%(18 \mathrm{mo})$ \\
\hline Ried et al, $2012^{7}$ & $n=8$ & Cisplatin $\left(100-150 \mathrm{mg} / \mathrm{m}^{2} \mathrm{BSA}\right)$ & $0 \%$ & $88 \%(22 \mathrm{mo})$ & $88 \%(22 \mathrm{mo})$ \\
\hline Yellin et al, $2013^{15}$ & $n=35$ & $\begin{array}{l}\text { Cisplatin }\left(100 \mathrm{mg} / \mathrm{m}^{2} \mathrm{BSA}\right)+ \\
\text { doxorubicin }(50-60 \mathrm{mg})\end{array}$ & $2.5 \%$ & $48-61 \%(5 \mathrm{y})$ & $\begin{array}{l}67-81 \%(5 \mathrm{y}), \\
\text { thymic } \\
\text { carcinoma } 0 \%\end{array}$ \\
\hline $\begin{array}{l}\text { Ambrogi et al, } \\
2016^{20}\end{array}$ & $\begin{array}{l}n=13 \text { (pleural } \\
\text { recurrences) }\end{array}$ & $\begin{array}{l}\text { Cisplatin }\left(80 \mathrm{mg} / \mathrm{m}^{2} \mathrm{BSA}\right)+ \\
\text { doxorubicin }\left(25 \mathrm{mg} / \mathrm{m}^{2} \mathrm{BSA}\right)\end{array}$ & $0 \%$ & $77 \%(64 \mathrm{mo})$ & $92 \%(5 \mathrm{y})$ \\
\hline $\begin{array}{l}\text { Maury et al, } \\
2017^{13}\end{array}$ & $n=19$ & $\begin{array}{l}\text { Cisplatin }\left(50 \mathrm{mg} / \mathrm{m}^{2} \mathrm{BSA}\right)+ \\
\text { mitomycin }\left(25 \mathrm{mg} / \mathrm{m}^{2} \mathrm{BSA}\right)\end{array}$ & $0 \%$ & $50 \%(42 \mathrm{mo})$ & $86 \%(5 \mathrm{y})$ \\
\hline
\end{tabular}

Abbreviations: BSA, body surface area; HITOC, hyperthermic intrathoracic chemotherapy.

In the present study, the recurrence-free 5-year survival of patients with stage IVa thymic tumors after multimodal treatment including HITOC was $53.8 \%$, with an average recurrencefree interval of 53.7 months. Our study exceeds the very good recurrence-free interval of 42 months from a study of 19 patients treated with additional HITOC. ${ }^{13}$ In the literature, multimodal therapy without HITOC resulted in distinctly lower 5-year recurrence-free rates of 13.3 to $33.6 \%{ }^{27,28}$ Intrapleural chemotherapy, thus, offers the opportunity to kill residual tumor cells that persist even after complete macroscopic removal and lead to local recurrence. ${ }^{7-9}$ Additional hyperthermia increases the cytotoxic effect by improving penetration depth and reducing chemotherapeutic resistance. ${ }^{21}$

Even though recurrence-free survival and overall survival are only partially linked in thymomas (recurrence does not necessarily lead to death and deaths are often not due to recurrence), good recurrence-free survival is also reflected in the 5-year overall-survival rate of $80.1 \%{ }^{29}$ Other studies of patients with stage IVa thymomas and HITOC found encouraging 5-year survival rates of 67 to $92 \%$ (- Table 4). ${ }^{13-15,20}$ However, stage IVa patients who did not receive HITOC have published 5-year survival rates ranging between 53 and 87\%. 5,6

The good overall-survival of surgically treated patients with thymoma stage IVa is an expression of the low metastatic potential of thymomas. One possible reason for this positive result may also lie in the high proportion of macroscopically completely resected tumors ( $86.2 \%$ in our study), since resection status is known to be an important prognostic factor. ${ }^{2}$ Only in four cases with involvement of the great vessels or intra-/retroperitoneal spreading a postoperative R2 situation was given.

Another important prognostic factor is the histological subtype. Patients with thymic carcinoma (WHO type C) showed significantly worse prognosis in the present study (0 vs. 83.1-91.7\% 5-year survival rates). Especially studies with high survival rates have excluded thymic carcinomas., Thus, these patients with stage IVa thymic carcinomas seem not to benefit from surgery, and therefore, HITOC also had no significant effect.
There was no difference in overall-survival between primary stage IVa thymic tumors and patients with pleural recurrence. Therefore, in patients with pleural recurrence of thymoma, surgery and HITOC can be indicated. Until now, no significant difference in survival was observed by resection status ( 85.5 vs. $50 \%$ ), choice of chemotherapeutic agents for HITOC, or the concentration of cisplatin. However, a longer follow-up might be required for this tumor entity.

The extent of surgery (P/D vs. EPP) in our study did not affect survival. Also in the literature, lung-protecting procedures such as $\mathrm{P} / \mathrm{D}$ and $\mathrm{eP} / \mathrm{D}$ showed similar survival but lower complication rates compared with EPP. ${ }^{30}$ Due to this fact, $\mathrm{P} / \mathrm{D}$ and $\mathrm{eP} / \mathrm{D}$ were preferred depending on the patient's condition, and complete resection of the tumor could be achieved in $88.5 \%$ of these patients.

This study has limitations due to its retrospective nature and single-center design in a selected and heterogeneous group of patients. Due to this special tumor entity and advanced stage, the number of patients is limited. Furthermore, there was no control group of patients who did not receive HITOC. A longer follow-up might substantiate our findings.

\section{Conclusion}

Surgical cytoreduction with HITOC is safe and feasible in selected patients with thymic malignancies and pleural dissemination. It offers encouraging survival rates, both in primary and secondary (pleural recurrence) stage IVa thymomas. In contrast, thymic carcinomas show a considerably lower survival rate and should be treated as a distinct tumor entity. To improve local tumor control resulting in prolonged recurrence-free survival, HITOC with cisplatin can be used in addition to surgical cytoreduction. Severe HITOC-associated complications are rare and renal complications can be reduced by fluid balancing and cytoprotection.

Conflict of Interest

None declared. 


\section{References}

1 Detterbeck FC, Parsons AM. Thymic tumors. Ann Thorac Surg 2004;77(05):1860-1869

2 Ried M, Guth H, Potzger T, et al. Surgical resection of thymoma still represents the first choice of treatment. Thorac Cardiovasc Surg 2012;60(02):145-149

3 Ströbel P, Bauer A, Puppe B, et al. Tumor recurrence and survival in patients treated for thymomas and thymic squamous cell carcinomas: a retrospective analysis. JClin Oncol 2004;22(08): 1501-1509

4 Margaritora S, Cesario A, Cusumano G, et al. Thirty-five-year follow-up analysis of clinical and pathologic outcomes of thymoma surgery. Ann Thorac Surg 2010;89(01):245-252, discussion 252

5 Moser B, Fadel E, Fabre D, et al. Surgical therapy of thymic tumours with pleural involvement: an ESTS Thymic Working Group Project. Eur J Cardiothorac Surg 2017;52(02):346-355

6 Falkson CB, Bezjak A, Darling G, et al; Lung Cancer Disease Site Group of Cancer Care Ontario's Program in Evidence-Based Care. The management of thymoma: a systematic review and practice guideline. JThorac Oncol 2009;4(07):911-919

7 Ried M, Potzger T, Braune N, et al. Cytoreductive surgery and hyperthermic intrathoracic chemotherapy perfusion for malignant pleural tumours: perioperative management and clinical experience. Eur J Cardiothorac Surg 2013;43(04):801-807

8 Liu HC, Chen YJ, Tzen CY, Huang CJ, Chang CC, Huang WC. Debulking surgery for advanced thymoma. Eur J Surg Oncol 2006;32(09):1000-1005

9 Kaba E, Ozkan B, Erus S, Duman S, Cimenoglu B, Toker A. Role of surgery in the treatment of Masaoka Stage IVa thymoma. Ann Thorac Cardiovasc Surg 2018;24(01):6-12

10 Ruffini E, Mancuso M, Oliaro A, et al. Recurrence of thymoma: analysis of clinicopathologic features, treatment, and outcome. J Thorac Cardiovasc Surg 1997;113(01):55-63

11 de Bree E, van Ruth S, Baas P, et al. Cytoreductive surgery and intraoperative hyperthermic intrathoracic chemotherapy in patients with malignant pleural mesothelioma or pleural metastases of thymoma. Chest 2002;121(02):480-487

12 Wilkins KB, Sheikh E, Green R, et al. Clinical and pathologic predictors of survival in patients with thymoma. Ann Surg 1999;230(04):562-572, discussion 572-574

13 Maury JM, Girard N, Tabutin M, et al. Intra-thoracic chemohyperthermia for pleural recurrence of thymoma. Lung Cancer 2017;108:1-6

14 Refaely Y, Simansky DA, Paley M, Gottfried M, Yellin A. Resection and perfusion thermochemotherapy: a new approach for the treatment of thymic malignancies with pleural spread. Ann Thorac Surg 2001;72(02):366-370

15 Yellin A, Simansky DA, Ben-Avi R, et al. Resection and heated pleural chemoperfusion in patients with thymic epithelial malignant disease and pleural spread: a single-institution experience. J Thorac Cardiovasc Surg 2013;145(01):83-87, discussion 87-89

16 Zellos L, Richards WG, Capalbo L, et al. A phase I study of extrapleural pneumonectomy and intracavitary intraoperative hyperthermic cisplatin with amifostine cytoprotection for malignant pleural mesothelioma. JThorac Cardiovasc Surg 2009;137 (02):453-458
17 Burt BM, Richards WG, Lee HS, et al. A phase I trial of surgical resection and intraoperative hyperthermic cisplatin and gemcitabine for pleural mesothelioma. JThorac Oncol 2018;13(09): 1400-1409

18 Sugarbaker DJ, Gill RR, Yeap BY, et al. Hyperthermic intraoperative pleural cisplatin chemotherapy extends interval to recurrence and survival among low-risk patients with malignant pleural mesothelioma undergoing surgical macroscopic complete resection. J Thorac Cardiovasc Surg 2013;145(04):955-963

19 Richards WG, Zellos L, Bueno R, et al. Phase I to II study of pleurectomy/decortication and intraoperative intracavitary hyperthermic cisplatin lavage for mesothelioma. JClin Oncol 2006; 24(10):1561-1567

20 Ambrogi MC, Korasidis S, Lucchi M, et al. Pleural recurrence of thymoma: surgical resection followed by hyperthermic intrathoracic perfusion chemotherapy. Eur J Cardiothorac Surg 2016;49 (01):321-326

21 Ratto GB, Civalleri D, Esposito M, et al. Pleural space perfusion with cisplatin in the multimodality treatment of malignant mesothelioma: a feasibility and pharmacokinetic study. JThorac Cardiovasc Surg 1999;117(04):759-765

22 Ried M, Potzger T, Braune N, et al. Local and systemic exposure of cisplatin during hyperthermic intrathoracic chemotherapy perfusion after pleurectomy and decortication for treatment of pleural malignancies. J Surg Oncol 2013;107(07):735-740

23 Madias NE, Harrington JT. Platinum nephrotoxicity. Am J Med 1978;65(02):307-314

24 Tilleman TR, Richards WG, Zellos L, et al. Extrapleural pneumonectomy followed by intracavitary intraoperative hyperthermic cisplatin with pharmacologic cytoprotection for treatment of malignant pleural mesothelioma: a phase II prospective study. J Thorac Cardiovasc Surg 2009;138(02):405-411

25 McKibbin T, Cheng LL, Kim S, et al. Mannitol to prevent cisplatininduced nephrotoxicity in patients with squamous cell cancer of the head and neck (SCCHN) receiving concurrent therapy. Support Care Cancer 2016;24(04):1789-1793

26 Weichert-Jacobsen KJ, Bannowski A, Küppers F, Loch T, Stöckle M. Direct amifostine effect on renal tubule cells in rats. Cancer Res 1999;59(14):3451-3453

27 Kim BK, Cho BC, Choi HJ, et al. A single institutional experience of surgically resected thymic epithelial tumors over 10 years: clinical outcomes and clinicopathologic features. Oncol Rep 2008;19 (06):1525-1531

28 Yano M, Sasaki H, Yukiue H, et al. Thymoma with dissemination: efficacy of macroscopic total resection of disseminated nodules. World J Surg 2009;33(07):1425-1431

29 Detterbeck FC, Stratton K, Giroux D, et al; Staging and Prognostic Factors Committee; Members of the Advisory Boards; Participating Institutions of the Thymic Domain. The IASLC/ITMIG Thymic Epithelial Tumors Staging Project: proposal for an evidence-based stage classification system for the forthcoming (8th) edition of the TNM classification of malignant tumors. JThorac Oncol 2014;9 (09, Suppl 2):S65-S72

30 Ambrogi MC, Bertoglio P, Aprile V, et al. Diaphragm and lungpreserving surgery with hyperthermic chemotherapy for malignant pleural mesothelioma: a 10-year experience. JThorac Cardiovasc Surg 2018;155(04):1857-1866.e2 